\title{
ORAL CAVITY STATUS OF LONG-TERM HEMODIALIZED PATIENTS VS. THEIR SOCIO-ECONOMIC STATUS
}

\author{
Agata Trzcionka, Henryk Twardawa, Katarzyna Mocny-Pachońska, Marta Tanasiewicz \\ Medical University of Silesia in Katowice, Bytom, Poland \\ Faculty of Medical Science in Zabrze, Department of Conservative Dentistry with Endodontics
}

\begin{abstract}
Background: The chronic kidney disease, blood hypertension and diabetes are recognized as civilization diseases that affect more and more people. The probability of encountering a patient suffering from these diseases is increasing. As such, it appears crucial to better understand the specific dental needs of such groups of patients. The aim of the work was to assess the oral hygiene status and the needs of patients suffering from the end-stage chronic kidney disease, arterial hypertension or/and diabetes. Material and Methods: Two hundred and twenty eight patients were included in the research. One hundred and eighty patients were hemodialized in Diaverum dialysis stations and 48 patients were from the Conservative Dentistry with Endodontics Clinic of the Academic Centre of Dentistry in Bytom, Silesian Medical University in Katowice, and from the Dentistry Division of the Arnika Clinic in Zabrze, and were not not diagnosed with any of the diseases mentioned. The research scheme was divided into 3 parts, consisting of an analysis of the general health socio-economic status, a survey and an assessment of oral health. Results: The patients who were not suffering from any of the discussed diseases were more aware of how to properly perform hygienic procedures. Most of the patients from both the control and examined groups were not using any rinsing solutions. A higher percentage of patients in the control group was using dental floss, changing their toothbrush every 3 months and brushing their teeth for $\geq 2 \mathrm{~min}$. The Aproximal Plaque Index and the Oral Hygiene Index-Simplified values in the control group were significantly lower in comparison to the examined group. Conclusions: The socio-economic status of hemodialized patients was low, which in most cases was a result of the difficulties in starting a job. Due to the lower standards of life, the neglect of oral hygiene maintenance and its consequences could be observed. Med Pr. 2020;71(3):279-88
\end{abstract}

Key words: chronic diseases, socio-economic status, end-stage chronic kidney disease, oral health, hemodialysis, health maintenance

Corresponding author: Agata Trzcionka, Medical University of Silesia in Katowice, Faculty of Medical Science in Zabrze, Department of Conservative Dentistry with Endodontics, pl. Akademicki 17, 41-902 Bytom, Poland, e-mail: atrzcionka@sum.edu.pl

Received: October 31, 2019, accepted: February 7, 2020

\section{INTRODUCTION}

Civilization diseases are defined as global and common diseases which result from an evolutionary progress, which is why they are sometimes referred to as "diseases of the 21st century" [1]. Civilization diseases include endstage chronic kidney disease, blood hypertension and diabetes. The end-stage chronic kidney disease causes a huge number of complications in many organs and systems. Drug therapies often lead to various pathologies in the oral cavity such as tooth decay, periodontal disease, oral mucosal disease, or decreased saliva secretion.

Decreased saliva secretion leads to an increased accumulation of dental plaque, its mineralization, and prolonged surge, which in turn leads to gingivitis and periodontitis. Moreover, the natural mechanism for plaque removal is undermined by the deficit of the buffering systems in saliva, which leads to rapid tooth decay. Symptoms involving the mucous membrane (such as atrophy, Candida albicans infections, or lesions), coupled with the atrophy of mandibular and maxillary bones, may cause difficulties or even prevent the usage of dental prosthetics [2]. At the same time, the dependence of the rhythm of the day on the disease and hemodialysis, not having a day job and the socio-economic status of the family whose member is suffering from a chronic disease, are the factors that contribute to the fact that many patients are not being properly taken care of in terms of dentistry $[3,4]$.

The aim of this work was to assess the socio-economic status vs. the oral hygiene status and the needs of patients suffering from the end-stage chronic kidney disease, arterial hypertension or/and diabetes.

\section{MATERIAL AND METHODS}

The study was conducted on 228 patients, 180 of whom were long-term hemodialized, treated in Diaverum di- 
alysis stations, and the remaining 48 were treated by the Conservative Dentistry with Endodontics Clinic of the Academic Center of Dentistry in Bytom, Medical University of Silesia in Katowice, in addition to patients of the Dentistry Division of the Arnika Clinic in Zabrze.

The examined group (EG) consisted of 180 patients treated in Diaverum dialysis stations in Katowice, Głubczyce, Warsaw and Kraków, who were diagnosed with the end-stage chronic kidney disease. The patients were considered to have blood hypertension based on at least 1 of the blood tension values of $\geq 140 / 90 \mathrm{~mm} \mathrm{Hg}$, obtained in a few measurements over the course of at least 2 medical check-ups. Patients with diabetes are diagnosed on the basis of the WHO recommendations with a fasting plasma glucose test and the Impaired Glucose Tolerance (IGT) test. The patients were divided into 4 subgroups on the basis of the general disease they suffer from, into the end-stage chronic disease $(R)$, endstage chronic disease and hypertension $(\mathrm{R}+\mathrm{H})$, endstage chronic disease and diabetes $(\mathrm{R}+\mathrm{D})$, and end-stage chronic disease, hypertension and diabetes $(\mathrm{R}+\mathrm{H}+\mathrm{D})$ subgroups. The assignment and number of patients in particular subgroups are presented in Table 1.

The control group (CG) was composed of patients from the Conservative Dentistry with Endodontics Clinic of the Academic Center of Dentistry in Bytom, Medical University of Silesia in Katowice, and patients who had not been previously diagnosed with any of the civilization diseases included in the examined group. That group consisted of 48 people (Table 1). The project of the research obtained the consent from the Bioethics Commission of the Medical University of Silesia in Katowice (resolution No. KNW/0022/ $\mathrm{KBI} / 72 / \mathrm{I} /$ of July 6,2010 .)

\section{Inclusion criteria}

\section{The examined group}

The examined group consisted of patients aged $>40$, suffering from the diagnosed end-stage chronic kidney disease, blood hypertension and/or diabetes for at least 2 years, who had given their written consent to take part in the research.

\section{The control group}

The control group consisted of patients aged $>40$, who were not diagnosed with any of the civilization diseases included in the examined group, who had given their written consent to take part in the research.

\section{Exclusion criteria}

Patients were excluded if they were aged $<40$, did not agree to take part in the research, did not demonstrate a will to cooperate, were pregnant, were in the state of an exacerbated general disease, were incapacitated, or had suffered from civilization diseases for $<2$ years.

The research was conducted by means of questionnaires concerning the socio-economic status and hygienic habits. The included questions and possible answers are presented in Table 2.

In the next stage of the research, the following indices were assessed:

Aproximal Plaque Index (API) by Lange - a yes/no decision is made with regards to whether the examined interproximal surfaces are covered by plaque $(+)$ or not $(-)$. The index is calculated as per the following formula:

$$
\text { API }=\frac{\text { No. of plaque }(+) \text { sites }}{\text { No. of sites examined }} \times 100 \%
$$

Table 1. Assignment and number of patients in particular groups of patients that took part in the research that aimed at assessing the socio-economic status vs. the oral hygiene status and the needs of patients suffering from the end-stage chronic kidney disease, arterial hypertension or/and diabetes

\begin{tabular}{|c|c|c|}
\hline Group & Characteristics & $\begin{array}{l}\text { Patients } \\
\text { [n] }\end{array}$ \\
\hline \multicolumn{3}{|l|}{ Examined } \\
\hline subgroup R & patients diagnosed with the end-stage chronic kidney disease & 42 \\
\hline subgroup $\mathrm{R}+\mathrm{H}$ & patients diagnosed with the end-stage chronic kidney disease and hypertension & 79 \\
\hline subgroup $\mathrm{R}+\mathrm{D}$ & patients diagnosed with the end-stage chronic kidney disease and diabetes & 16 \\
\hline subgroup $\mathrm{R}+\mathrm{H}+\mathrm{D}$ & patients diagnosed with the end-stage chronic kidney, hypertension and diabetes & 43 \\
\hline Control & patients that were not diagnosed with the end-stage chronic kidney disease, blood hypertension or diabetes & 48 \\
\hline
\end{tabular}

D - diabetes, $\mathrm{H}$ - hypertension, $\mathrm{R}$ - end-stage chronic disease. 
Table 2. Questionnaire concerning the socio-economic status and hygienic habits of patients that took part in the research that aimed at assessing the socio-economic status vs. the oral hygiene status and the needs of patients suffering from the end-stage chronic kidney disease, arterial hypertension or/and diabetes

\begin{tabular}{|c|c|}
\hline Question & Possible answer \\
\hline 1. Approximate family income & $\begin{array}{l}\text { - much lower than the national average } \\
\text { - lower than the national average } \\
\text { - the national average } \\
\text { - higher than the national average } \\
\text { - much higher than the national average }\end{array}$ \\
\hline 2. Does the income cover all the family's monthly expenses? & $\begin{array}{l}\text { - no, it does not } \\
\text { - sometimes it does, sometimes it does not } \\
\text { - yes, it does but I am not able to save any money } \\
\text { - yes, it does and I am able to save some money }\end{array}$ \\
\hline $\begin{array}{l}\text { 3. Has it happened that during the last } 12 \text { months, due to the lack of money, } \\
\text { you were not able to pay the bills? }\end{array}$ & $\begin{array}{l}- \text { yes } \\
\text { - no }\end{array}$ \\
\hline 4. When did your last dental appointment take place? & $\begin{array}{l}\text { - shorter than } 3 \text { months ago } \\
\text { - } 3-6 \text { months ago } \\
\text { - a year ago } \\
\text { - I do not remember }\end{array}$ \\
\hline 5. When did you start to take care of your oral hygiene? & $\begin{array}{l}\text { - as a teenager } \\
\text { - around } 20 \text { years of age } \\
\text { - around } 30 \text { years of age } \\
\text { - after } 30 \text { years of age }\end{array}$ \\
\hline 6. How many times a day do you brush your teeth? & $\begin{array}{l}\text { - I do not brush my teeth } \\
\text { - once a day } \\
\text { - twice a day } \\
\text { - } 3 \text { times a day }\end{array}$ \\
\hline 7. Do you use any mouthwash? & $\begin{array}{l}- \text { yes } \\
\text { - no }\end{array}$ \\
\hline 8. Do you use dental floss? & $\begin{array}{l}\text { - yes } \\
\text { - no }\end{array}$ \\
\hline 9. How often do you change your toothbrush? & $\begin{array}{l}\text { - every } 3 \text { months } \\
\text { - every } 6 \text { months } \\
\text { - once a year } \\
\text { - occasionally }\end{array}$ \\
\hline 10. How much time do you spend on hygienic procedures? & $\begin{array}{l}- \text { around } 1 \mathrm{~min} \\
- \text { around } 2 \mathrm{~min} \\
-\geq 2 \text { min } \\
- \text { I do not know }\end{array}$ \\
\hline
\end{tabular}

The examination was done using a dental probe. The minimal number of the examined interproximal surfaces was 10-12, necessarily between molar teeth. Quadrants 1 and 3 were examined from the oral aspect, and quadrants 2 and 4 were examined from the facial aspect.

Based on the results, the oral hygiene conditions of the examined subjects could be determined as follows:

- $100-70 \%$ - poor oral hygiene,

- 69-40\% - insufficient oral hygiene,

- 39-25\% - pretty good oral hygiene,

- $<25 \%$ - optimum oral hygiene.
Oral Hygiene Index-Simplified (OHI-S) by Green and Vermillion - the index has 2 components, i.e., the Debris Index and the Calculus Index. Each of these indices is based on numerical determinations representing the amount of debris or calculus found on the preselected tooth surface. The 6 surfaces examined for OHI-S are selected from 4 posterior and 2 anterior teeth.

The examination was done using a dental mirror. Overall, 6 teeth were examined, including 16 and 26 on the buccal surfaces, 26 and 46 on the lingual surfaces, and 11 and 31 on the labial surfaces. The re- 
sult of the examination was assigned a value between 0 and 3 :

- 0 - no debris or calculus;

- 1 - soft debris or supragingival calculus, covering no more than one-third of the exposed surface;

- 2 - soft debris or supragingival calculus, covering no more than two-thirds of the exposed tooth surface, or the presence of flecks of subgingival calculus around the cervical portion of the tooth, or both;

- 3 - soft debris or supragingival calculus, covering more than two-thirds of the exposed tooth surface, or a continuous heavy band of subgingival calculus around the cervical portion of the tooth, or both.

The results obtained for particular teeth (surfaces) were added and then divided by the number of the examined teeth. The possible results range $0-3$ for the Debris and Calculus Indices, and between 0-6 for the OHI-S values.

\section{Statistical analysis}

For the quantitative variables like OHI-S and API, an analysis with the Shapiro-Wilk test was performed in order to verify the compatibility of these variables' distribution with the normal distribution. Due to the occurrence of the grounds for rejecting the zero hypothesis with regards to the compatibility of the distribution with the normal distribution ( $\mathrm{p}<0.05)$, the nonparametric tests were done. The Kruskall-Wallis test was performed in order to assess differences in the averages of the parameters across the 5 groups. In the case of significant differences between the averages, the Mann-Whitney $U$ test was performed to verify the accuracy of these differences. All these tests were performed using the IBM's SPSS Statistics 23 program, and $\mathrm{p}<0.05$ was considered indicative of a statistically significant result.

\section{RESULTS}

\section{Characteristics of the groups}

The average age in the control group was 52.71, and the group was composed of 15 men and 33 women. The subgroup of hemodialized patients with no general disease included 25 men and 17 women, and their average age was 67.21. The subgroup of hemodialized patients with hypertension included 48 men and 31 women, whose average age was 62.54 . The average age of hemodialized patients with diabetes ( 10 men and 6 women) was 70.19 , and the average age of hemodialized patients with hypertension and diabetes (27 men and 16 women) was 72.86. All the hemodialized patients underwent hemodialysis 3 times a week, with the procedure lasting 5-6 h.

\section{Socio-economic status questionnaire}

The analysis of the results proved that there were statistically significant differences in the approximate family income between particular groups of patients, $\chi^{2}(16)=$ $78.71, p<0.001, \eta=0.45$. The percentage of the patients with income much lower than the national average was significantly higher in hemodialized patients with hypertension, with hypertension and diabetes, and with diabetes, than in patients from the control group and in hemodialized patients with no other general disease. The patients from the control group more often declared to have income higher than the national average (Table 3, Figure 1).

The $\chi^{2}$ test proved that there were statistically significant differences in answers to the question: "Does the income cover all the family's monthly expenses?" between the particular groups of patients, $\chi^{2}(12)=46.89$, $p<0.001, \eta=0.38$. The percentage of patients who declared that their income did not cover all the expenses was significantly higher in hemodialized patients with hypertension, with hypertension and diabetes, and with diabetes, than in hemodialized patients who were not diagnosed with any other general disease and in the control group. The patients from the control group often declared that they were able to save some money (Figure 2). The $\chi^{2}$ test also proved that there were statistically significant differences in answers to the question: "Has it happened that during the last 12 months, due to the lack of money, you were not able to pay the bills?"

Table 3. Frequency and percentage distributions of answers to the questionnaire's questions regarding the socio-economic status of patients that took part in the research that aimed at assessing the socio-economic status vs. the oral hygiene status and the needs of patients suffering from the end-stage chronic kidney disease, arterial hypertension or/and diabetes

\begin{tabular}{lccccc}
\hline \multicolumn{1}{c}{ Question } & $\chi^{2}$ & df & p & $\eta$ \\
\hline $\begin{array}{l}\text { Approximate family income } \\
\begin{array}{l}\text { Does the income cover all the family's } \\
\text { monthly expenses? }\end{array}\end{array}$ & 48.71 & 16 & 0.000 & 0.45 \\
$\begin{array}{l}\text { Has it happened that during the last } \\
12 \text { months, due to the lack of money, } \\
\text { you were not able to pay the bills? }\end{array}$ & 27.98 & 4 & 0.000 & 0.38 \\
\hline
\end{tabular}




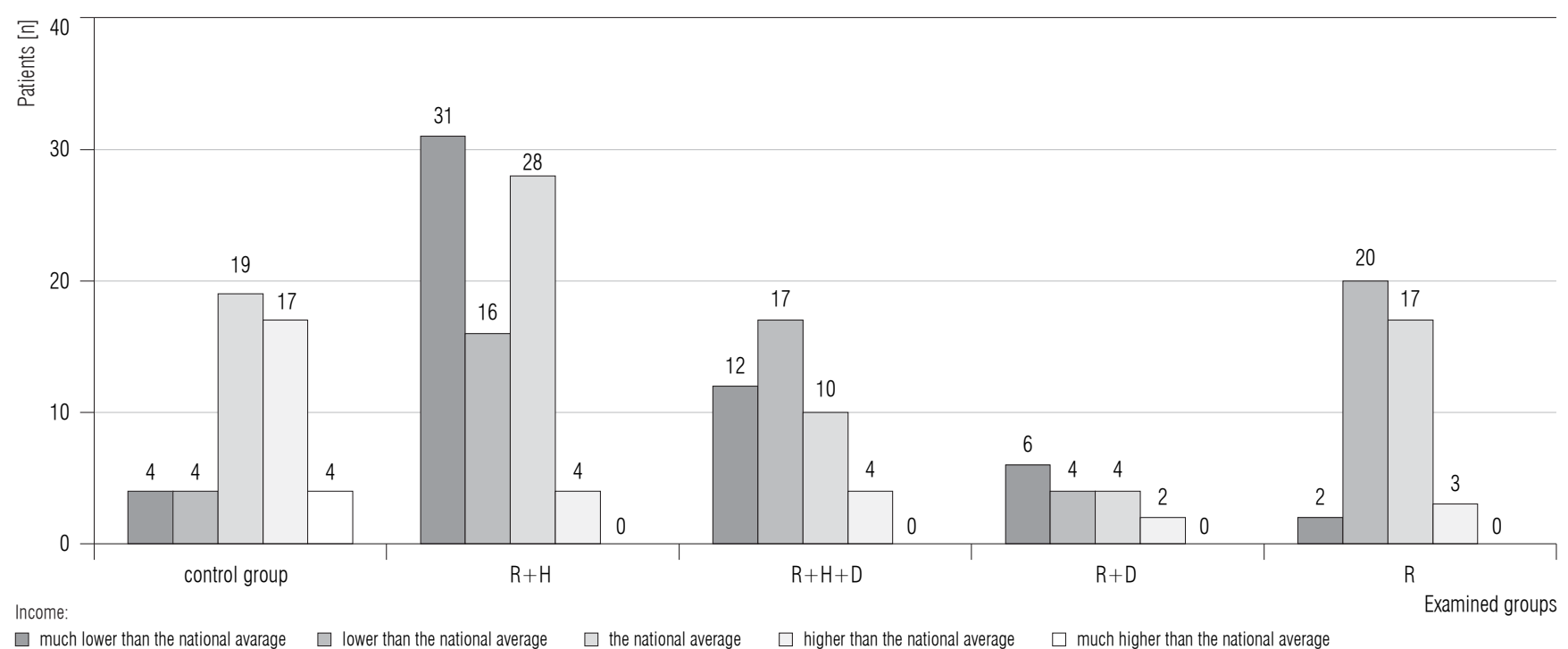

$\square$ much lower than the national avarage $\quad \square$ lower than the national average $\quad \square$ the national average $\quad \square$ higher than the national average $\quad \square$ much higher than the national average

Abbreviations as in Table 1.

Figure 1. Average income of the family in particular groups of patients that took part in the research that aimed at assessing the socio-economic status vs. the oral hygiene status and the needs of patients suffering from the end-stage chronic kidney disease, arterial hypertension or/and diabetes

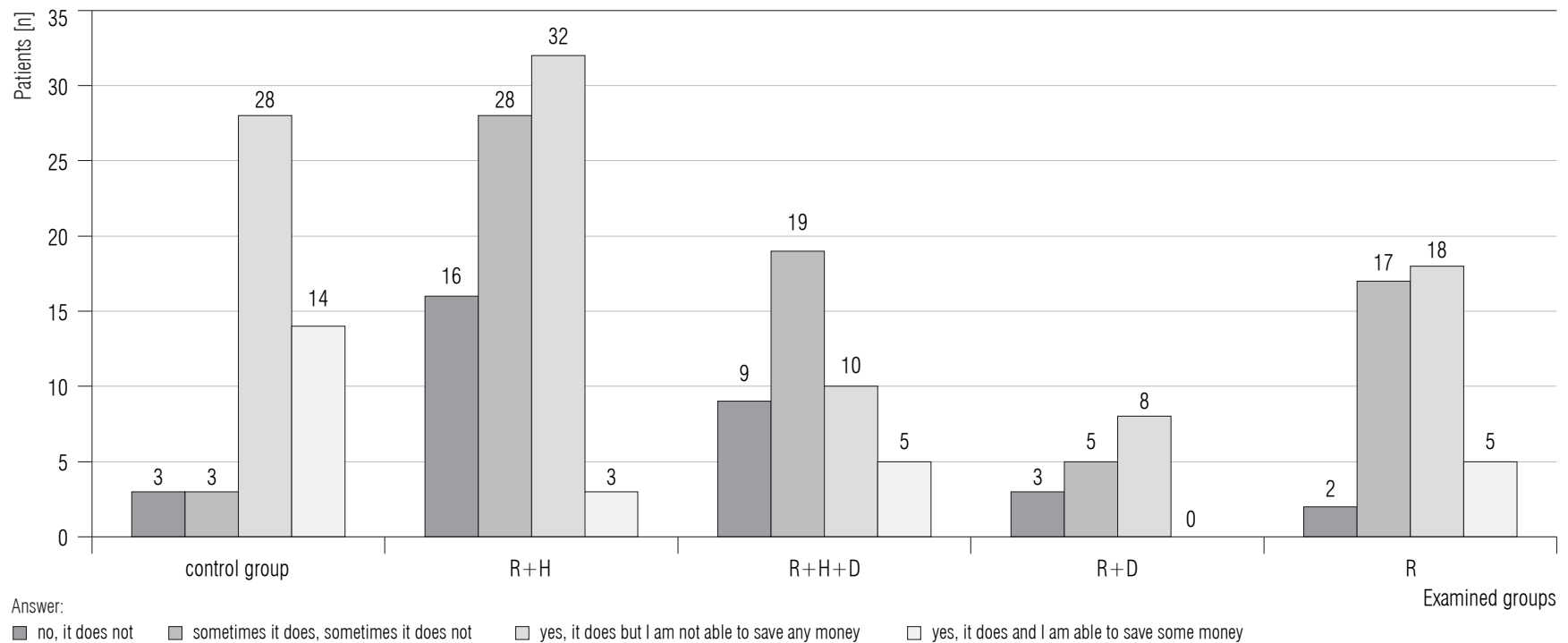

Abbreviations as in Table 1.

Figure 2. Answers to the question: "Does the income cover all the family's monthly expenses?" in particular groups of patients that took part in the research that aimed at assessing the socio-economic status vs. the oral hygiene status and the needs of patients suffering from the end-stage chronic kidney disease, arterial hypertension or/and diabetes

between the particular groups of patients, $\chi^{2}(4)=27.98$, $p<0.001, \eta=0.35$. The percentage of patients who replied "no" to that question was significantly higher in the control group (Figure 3).

\section{Oral hygiene habits questionnaire}

The frequency and percentage distributions of the answers to the questionnaire's questions are presented in Table 4.
There was a significantly higher percentage of patients who had visited a dentist during the past 3 months and had brushed their teeth 3 times a day among the patients who were not diagnosed with the end-stage chronic kidney disease, blood hypertension or diabetes. Most hemodialized patients had had their last appointment in a dental office a year before filling in the questionnaire or claimed not to remember when the last 


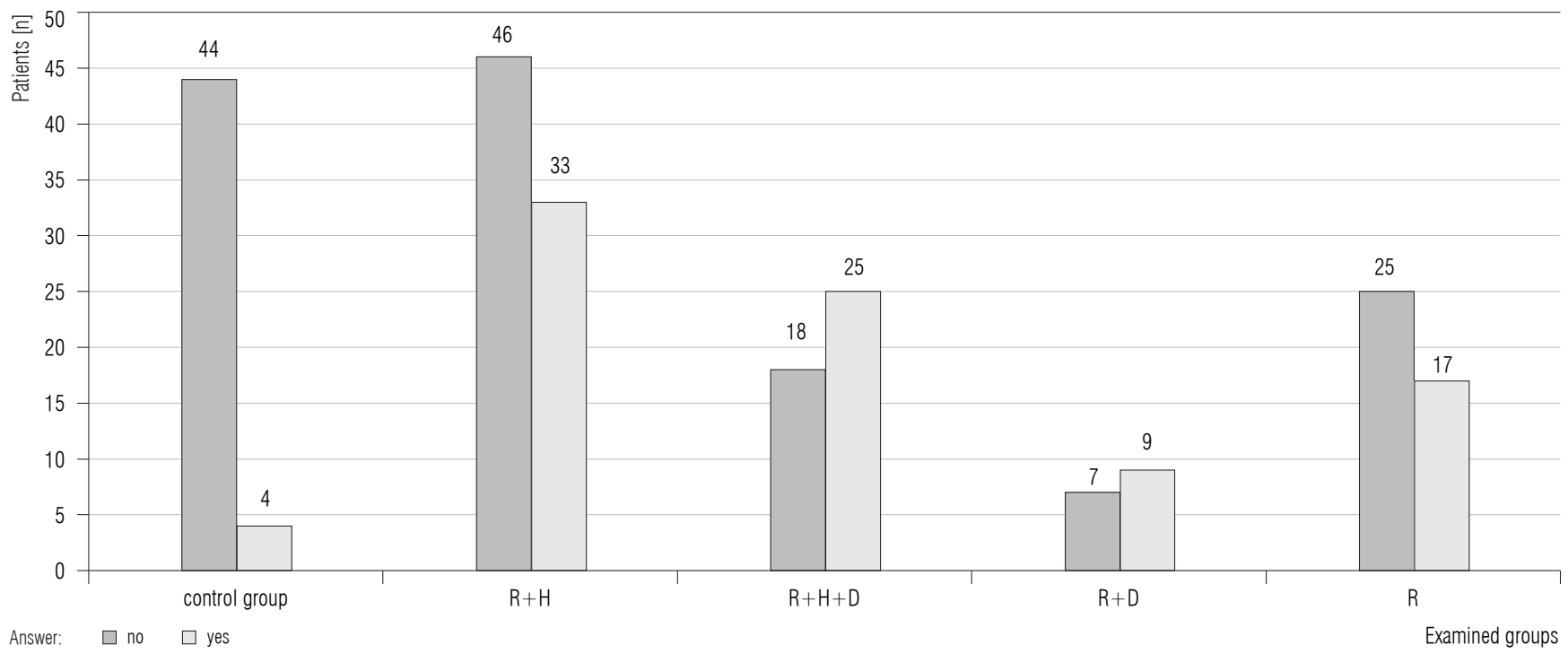

Abbreviations as in Table 1.

Figure 3. Answers to the question: "Has it happened that during the last 12 months, due to the lack of money, you were not able to pay the bills?" in particular groups of patients that took part in the research that aimed at assessing the socio-economic status vs. the oral hygiene status and the needs of patients suffering from the end-stage chronic kidney disease, arterial hypertension or/and diabetes

appointment had taken place. The $\mathrm{R}, \mathrm{R}+\mathrm{H}$, and $\mathrm{R}+\mathrm{H}+\mathrm{D}$ subgroups had the highest percentage of patients who declared not brushing their teeth at all.

In order to obtain information about the additional products used by the patients to properly maintain their oral hygiene, they were asked if they used any mouthwash or dental floss. Most patients from both the examined and control groups declared that they did not use any mouthwash. The percentage of patients who used dental floss and changed their toothbrush every 3 months was significantly higher among the patients belonging to the control group. In comparison to the patients in all subgroups of the examined group, there was a higher percentage of patients who brushed their teeth for $\geq 2 \mathrm{~min}$ in the control group, and a lower percentage of patients who brushed their teeth for $1 \mathrm{~min}$ or did not pay attention to the amount of time they brushed their teeth. Among hemodialized patients, the $\mathrm{R}+\mathrm{H}+\mathrm{D}$ subgroup had the highest percentage of patients who brushed their teeth for $1 \mathrm{~min}$. The highest percentage of patients who did not know how long their hygienic procedures lasted were also from the $\mathrm{R}+\mathrm{H}+\mathrm{D}$ subgroup.

\section{Aproximal Plaque Index}

The API values were not assessed in toothless patients or in patients with no interproximal surfaces. The medium values of API in particular subgroups were: CG -26.68 , $\mathrm{R}-74.55, \mathrm{R}+\mathrm{H}-69.40, \mathrm{R}+\mathrm{D}-95.71, \mathrm{R}+\mathrm{H}+\mathrm{D}-85.63$.
Those values made it possible to assess oral hygiene. The oral hygiene in the control group was relatively good. Hemodialized patients with blood hypertension had insufficient oral hygiene. Poor oral hygiene was seen in 3 subgroups of the examined group, i.e., in the $\mathrm{R}, \mathrm{R}+\mathrm{D}$, and $\mathrm{R}+\mathrm{H}+\mathrm{D}$ subgroups. Table 5 presents the medium values $(\mathrm{M})$ and standard deviations (SD) of the API values in both the examined and control groups.

The statistical analysis of API using the KruskallWallis test yielded significant differences between the groups, $\chi^{2}(4)=40.49, \mathrm{p}<0.001, \varepsilon^{2}=0.31$. The medium value of API in the control group was significantly lower in comparison to all the subgroups of the examined group $(\mathrm{R}, \mathrm{R}+\mathrm{H}, \mathrm{R}+\mathrm{D}, \mathrm{R}+\mathrm{H}+\mathrm{D})$. What is more, its medium value in the $\mathrm{R}+\mathrm{H}+\mathrm{D}$ subgroup was significantly higher than in the $\mathrm{R}+\mathrm{H}$ and $\mathrm{R}$ subgroups.

\section{Oral Hygiene Index-Simplified}

The OHI-S values were not assessed in patients who did not have the 6 indicated teeth or any other teeth in close proximity.

The highest medium values of OHI-S were observed in hemodialized patients. These values across the different subgroups were: $\mathrm{R}-1.70, \mathrm{R}+\mathrm{H}-2.27, \mathrm{R}+\mathrm{D}-3.11$, $\mathrm{R}+\mathrm{H}+\mathrm{D}-3.64$. In healthy patients, the medium value of OHI-S was 1.11 (the lowest one). Table 6 presents the medium values and standard deviations of OHI-S. 
Table 4. Frequency and percentage distributions of answers to the questionnaire's questions provided by patients that took part in the research that aimed at assessing the socio-economic status vs. the oral hygiene status and the needs of patients suffering from the end-stage chronic kidney disease, arterial hypertension or/and diabetes

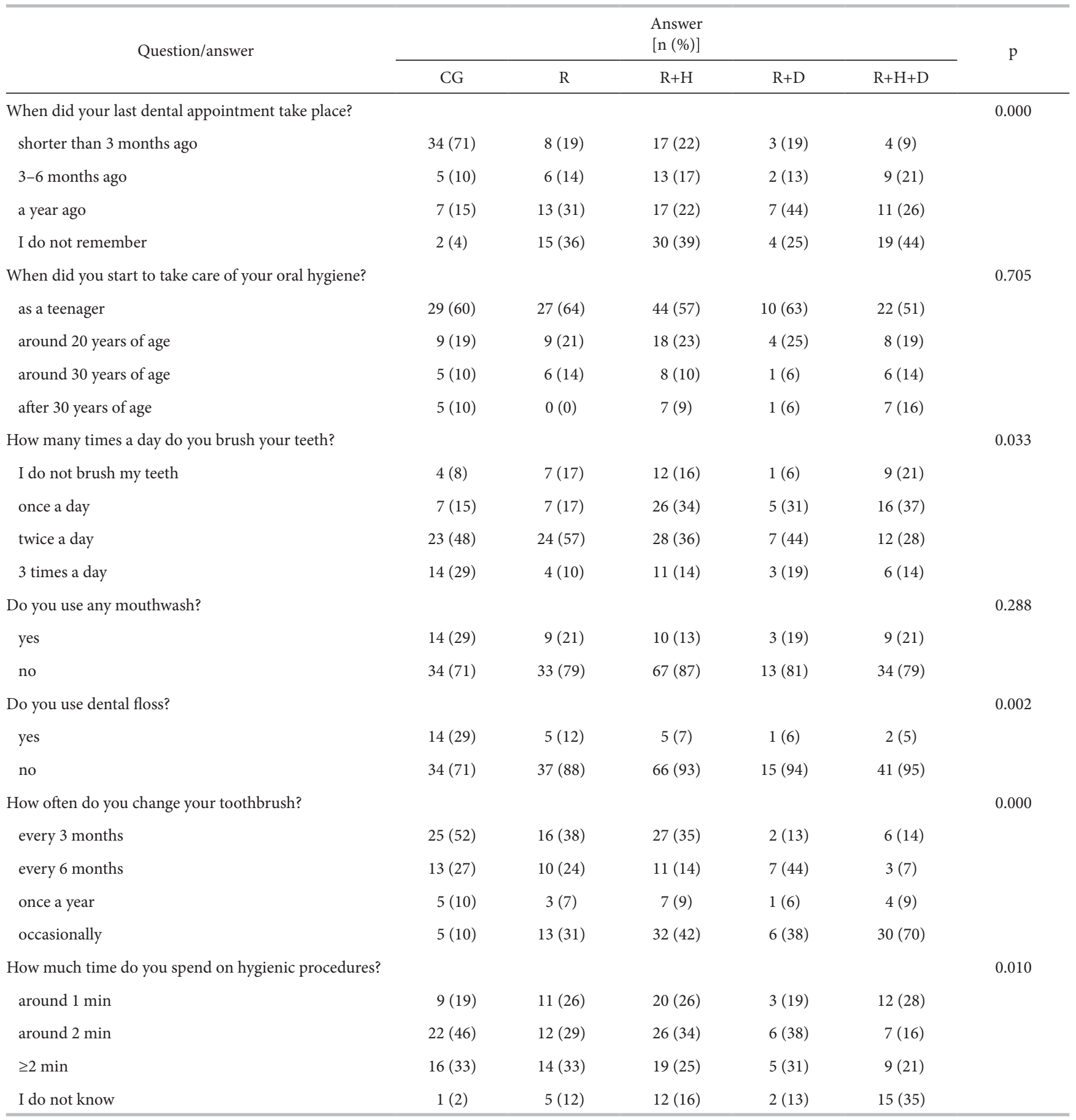

Abbreviations as in Table 1.

The statistical analysis of OHI-S using the Kruskall-Wallis test demonstrated significant differences between the groups, $\chi^{2}(4)=33.98, \mathrm{p}<0.001, \varepsilon^{2}=0.19$. The Mann-Whitney $U$ test showed that the medium value of $\mathrm{OHI}-\mathrm{S}$ in the control group was significantly lower than in patients belonging to the $\mathrm{R}+\mathrm{H}, \mathrm{R}+\mathrm{H}+\mathrm{D}, \mathrm{R}+\mathrm{D}$ and $\mathrm{R}$ subgroups. The medium value of OHI-S was significantly higher in the $\mathrm{R}+\mathrm{H}+\mathrm{D}$ subgroup in comparison to both the $\mathrm{R}+\mathrm{H}$ and $\mathrm{R}$ subgroups. Furthermore, it was significantly higher in the $\mathrm{R}+\mathrm{D}$ subgroup than in the $\mathrm{R}$ subgroup. 
Table 5. Medium values and standard deviations of the Aproximal Plaque Index (API) of patients that took part in the research that aimed at assessing the socio-economic status vs. the oral hygiene status and the needs of patients suffering from the end-stage chronic kidney disease, arterial hypertension or/and diabetes

\begin{tabular}{|c|c|c|c|}
\hline \multirow{2}{*}{ Group } & \multicolumn{3}{|c|}{ API } \\
\hline & M & $\mathrm{SD}$ & interpretation \\
\hline CG & 28.68 & 35.12 & pretty good oral hygiene \\
\hline $\mathrm{R}$ & 74.55 & 38.51 & poor oral hygiene \\
\hline $\mathrm{R}+\mathrm{H}$ & 69.40 & 43.44 & insufficient oral hygiene \\
\hline $\mathrm{R}+\mathrm{D}$ & 95.71 & 7.87 & poor oral hygiene \\
\hline $\mathrm{R}+\mathrm{H}+\mathrm{D}$ & 85.63 & 17.50 & poor oral hygiene \\
\hline
\end{tabular}

Abbreviations as in Table 1.

Table 6. Medium values and standard deviations of the Oral Hygiene Index-Simplified (OHI-S) of patients that took part in the research that aimed at assessing the socio-economic status vs. the oral hygiene status and the needs of patients suffering from the end-stage chronic kidney disease, arterial hypertension or/and diabetes

\begin{tabular}{llll}
\hline & & & OHI-S \\
\cline { 2 - 4 } & Group & $\mathrm{M}$ & $\mathrm{SD}$ \\
\hline CG & 1.11 & 1.78 \\
$\mathrm{R}$ & 1.70 & 1.70 & 2.17 \\
$\mathrm{R}+\mathrm{H}$ & 2.27 & 1.83 \\
$\mathrm{R}+\mathrm{D}$ & 3.11 & 2.20 \\
$\mathrm{R}+\mathrm{H}+\mathrm{D}$ & 3.64 & & 2.20 \\
\hline
\end{tabular}

Abbreviations as in Table 1.

\section{DISCUSSION}

The attempt to analyze the oral status of long-term hemodialized patients should be correlated with their socio-economic status. The questionnaire part of the research proved that there was a much higher percentage of people with income much lower than the national average, and that it was not enough to cover monthly expenses in patients suffering from the end-stage chronic kidney disease, hypertension and/or diabetes. It was found that healthy people more often declared that they earned enough money not only to pay their bills but also to save some money, and they also declared to pay all the bills on time.

The authors believe that the concentration on the general disease the patient suffers from is the main factor that influences his/her oral status. The patients undergoing hemodialysis have to fully change their life and adapt it to the rhythm of the dialyzes (in Diaverum dialysis stations, patients were hemodialized 3 times a week and each session lasted 5-6 h), which very often excluded them from having a full-time job. While talking to the patients, the authors could observe that they were resigned and discouraged. The patients very often had the feeling of being an encumbrance to their families. The authors' own observations about the psycho-social status of that group are confirmed in the analyses performed by others authors. Misiewicz et al., in their research conducted on 94 long-term hemodialized people, proved that their disease was the most important thing in the patients' lives [3]. An unsatisfactory level of dental care in hemodialized patients was also observed by Baranowicz-Gąszczyk et al., who found that problem especially in patients with a lower socioeconomic status [4].

The results of the analysis of oral hygiene based on the API values showed that hemodialized patients had insufficient oral hygiene that needed to be improved. The results of the OHI-S analysis were unsatisfactory for patients from the $\mathrm{R}+\mathrm{D}, \mathrm{R}+\mathrm{H}$ and $\mathrm{R}+\mathrm{H}+\mathrm{D}$ subgroups. The analysis of both indices mentioned proved that the maintenance of proper oral hygiene was especially problematic for hemodialized patients with diabetes. As previously mentioned, the analysis of oral hygiene indices was not advantageous for the hemodialized patients. It was crucial to concentrate on the ques- 
tionnaire results as well in order to analyze oral hygiene needs.

The results of the questionnaire concerning the last dental appointment indicated that people suffering from general diseases did not focus on doing regular check-ups at the dental office. The percentage of people who brushed their teeth 3 times a day was significantly higher in the control group than in the examined group. The $\mathrm{R}, \mathrm{R}+\mathrm{H}$ and $\mathrm{R}+\mathrm{H}+\mathrm{D}$ subgroups had the highest share of people who did not brush their teeth at all, potentially indicating their tendency to neglect their hygiene. This hypothesis could be confirmed with the answers to the questions concerning the use of additional products and the regularity of oral hygiene procedures (teeth brushing). This data suggested that maintaining oral hygiene was the most challenging for hemodialized patients with diabetes (API: $\mathrm{R}+\mathrm{D}-95.71, \mathrm{R}+\mathrm{H}+\mathrm{D}-$ 85.63; OHI-S: $\mathrm{R}+\mathrm{D}-3.11, \mathrm{R}+\mathrm{H}+\mathrm{D}-3.64)$, and that people suffering from general diseases were characterized by low awareness and not paying attention to performing the hygienic procedures on a regular basis.

The neglect or lower frequency of domestic oral procedures correlated with the lack of professional dental care in dental offices, as was observed by Craig [5] and Bayraktar et al. [6]. Parkar and Ajithkrishnan [7], on comparing the values of OHI-S obtained for hemodialized patients with those collected for healthy people, observed a deterioration in the oral hygiene status of hemodialized patients, which the authors believed to have been caused by the concentration of the patients on their general disease. They emphasized that hemodialysis was time-consuming and frequently caused a decrease in the self-assessment of the patients who had to depend only on themselves. They paid attention to the fact that patients were not informed about the necessity of proper hygiene practices and its influence on general health. They mentioned the need to provide professional dental care and the sources of information concerning oral hygiene maintenance.

Djemal et al. [8] observed that $32 \%$ of the examined hemodialized patients did not have their own dentist, up to $36 \%$ visited a dentist only in the case of acute pain, and $5 \%$ of hemodialized patients had never been to a dentist. What they highlighted was the fact that $12 \%$ of hemodialized patients had difficulties finding a dentist. Assessing domestic dental procedures revealed that $24 \%$ of hemodialized patients used only a manual toothbrush with a toothpaste, but also that hemodialized patients used mouthwash more frequently. The authors emphasized the need to provide professional den- tal care to patients with the end-stage chronic kidney disease, and the need for nephrologists and dentists to cooperate better. It appears crucial to provide an interdisciplinary group of medical professionals (including a dentist) to take care of hemodialized patients.

Ma et al. [9] observed that oral hygiene and the awareness of its importance in hemodialized patients were insufficient. In their research, those authors proved that dialyzed patients did not pay attention to daily hygienic procedures (up to half of them brushed their teeth only once a day). They also observed a lack of awareness among patients with the end-stage chronic kidney disease with regards to the necessity of maintaining oral hygiene. Chhokra et al. [10], on comparing the oral hygiene status of hemodialized patients with healthy ones, found, similar to these results, significantly lower OHI-S values in the control group in comparison to the examined group $(\mathrm{M}=1.69, \mathrm{SD}=0.55$ vs. $\mathrm{M}=3.59, \mathrm{SD}=1.15, \mathrm{p}=0.00)$. They also observed that oral hygiene worsened with time, as explained by a deterioration in the patients' physical condition which compromised their manual dexterity. However, this conclusion is questionable because the research was conducted on relatively young patients, on average $(38.03, \mathrm{SD}=7.41)$.

It is commonly claimed that hemodialized patients neglect their oral cavity hygiene due to the treatments of their general disease that frequently cause depression $[11,12]$. In 43 patients in the examined group $(24 \%)$, the symptoms of diabetic nephropathy in a wide spectrum of severity were observed. Those patients were treated by a group of specialists (a nephrologist, a diabetic specialist, a hypertension specialist), and their tendency of neglecting oral hygiene due to the general diseases was easily observed. The authors' own observations and the conclusions made after meetings with the hemodialized patients confirm that this group of patients was totally concentrated on the general disease and nothing else was as important for them as their chronic kidney disease. That can lead to the conclusion that the longer they undergo hemodialysis, the worse their oral cavity condition is.

That thesis was confirmed by Cengiz et al. [13], who examined the oral status of 68 hemodialized patients. They observed that the results of their research worsened over time, with significant changes being observed in the patients who had been undergoing hemodialysis for 10 years. Jain et al. [14], in their study on 400 hemodialized patients, observed that their oral status worsened with the duration of hemodialysis due to oral health negligence. They also put an emphasis on the need to 
implement a health promotion program in that group. Summing up the discussion, it can be said that the oral hygiene of hemodialized patients is strictly correlated with neglect, as validated by research performed by Parkar and Ajithkrishnan [7].

\section{CONCLUSIONS}

Hemodialized patients neglect hygienic procedures and have low awareness of the effectiveness of their oral hygiene maintenance procedures, which very often correlates with a poor socio-economic status of those patients being a result of a long-term therapy. This leads to an increased need for professional instruction concerning oral hygiene procedures, alongside a need to present them with additional products to help maintain proper oral hygiene in domestic settings. There is also a need to provide them with the professional care of dental hygienists.

\section{Ethical approval, consent to participate and human rights declaration}

Written informed consent for participation and publication was obtained from all the participants. The whole research was performed in accordance with the Declaration of Helsinki.

\section{REFERENCES}

1. Kitajewska W, Szeląg W, Kopański Z, Maslyak Z, Sklyarov I. Choroby cywilizacyjne i ich prewencja. J Clin Healthcare. 2014;1:3-7.

2. Wiczyńska-Borawska M, Myśliwiec M. Pacjent dializowany w gabinecie dentystycznym. Twój Przegl Stomatol. 2011; 7-8:72-5. Polish.

3. Misiewicz A, Różański J, Marchelek-Myśliwiec M, Wiśniecka M. Problemy psychospołeczne chorych przewlekle dializowanych. Post Nauk Med. 2010;3:188-91. Polish.

4. Baranowicz-Gąszczyk I, Jóźwiak L, Sykut J, Jaroszewicz E, Książek A. Stan uzębienia i leczenia protetycznego u pacjentów z przewlekłą chorobą nerek leczonych hemodializami.
Analiza przyczyn ograniczonego zaopatrzenia protetycznego. Nefrol Dial Pol. 2008;12:171-5. Polish.

5. Craig R.G. Interactions between chronic renal disease and periodontal disease - special review in periodontal medicine. Oral Dis. 2008;14:1-7.

6. Bayraktar G, Kurtulus I, Kazancioglu R, Bayramgurler I, Cintan S, Bural C. Effect of Educational Level on Oral Health in Pritoneal and Hemodialysis. Int J Dent. 2009;10:1-5.

7. Parkar SM, Ajithkrishnan CG. Periodontal status in patients undergoing hemodialysis. Indian J Nephrol. 2012;22: 246-50.

8. Djemal S, Rumjon A, Macdougall IC, Singh P, Warnakulasuriya S. Dental Attendance and Self-reported Oral Health Status of Renal Dialysis Patients: A Comparison of Results with the UK Adult Dental Health Survey. Oral Health Prev Dent. 2016;14:529-34, https://doi.org/10.3290/j.ohpd. a37138.

9. Ma L, Jin X, Cao Y, Xu Z, Xing S, Xu B. Periodontal status of patients undergoing peritoneal dialysis or hemodialysis. Int J Clin Exp Med. 2016;9:16759-64.

10. Chhokra M, Manocha S, Dodwad V, Gupta U, Vaish S. Establishing an Association between Renal Failure and Periodontal Health: A Cross Sectional Study. J Clin Diagn Res. 2013;7:2348-50.

11. Zawadzka B. Sytuacja psychologiczna chorych dializowanych i rola psychologa w ich adaptacji do leczenia. Nefrol Dial Pol. 2005;9:63-6.

12. Książek P, Makara-Studzińska M, Załuska A, Kaim R, Załuska W. Uwarunkowania rozwoju depresji u pacjentów ze schyłkową niewydolnością nerek, leczonych hemodializami. Przegl Lek. 2009;66:1036-9.

13. Cengiz MI, Sumer P, Cengiz S, Yavuz U. The effect of the duration of the dialysis in hemodialysis patients on dental and periodontal findings. Oral Dis. 2009;15:336-41, https://doi.org/10.1111/j.1601-0825.2009.01530.x.

14. Jain S, Singla A, Basavaraj P, Singh S, Singh K, Kundu H. Underlying kidney disease and duration of hemodialysis: An assessment of its effect on oral health. J Clin Diagn Res. 2014;8(5):ZC65-9, https://doi.org/10.7860/JCDR/2014/7853.4402.

This work is available in Open Access model and licensed under a Creative Commons Attribution-NonCommercial 3.0 Poland License - http://creativecommons.org/licenses/by-nc/3.0/pl/deed.en. 